\title{
ZU OSWALD VON WOLKENSTEIN.
}

Bei Oswald 80, 39 f. ed. Schatz weist das adelige fräulein die werbung des bauernburschen mit den worten ab: Ge smirb dein (den BC) wagen und drisch den rossen fueter, als ander dein geslächt. - Neidhart 55, 28 ff. ed. Haupt sagt von den dörperlichen tänzern, sie giengen ... alle tage als ein gesmirter wagen (sam ein geschmirbter $\mathrm{z}$ ), eben unde lise, niht bedrungen, daz in diu swert uf den versen klungen.

Diese beiden stellen führt schon das Mhd. wb. 3, 425, z. 32 f. als belege für die eigentliche bedeutung des verbs smirwen (in obd. quellen des 14. und 15. jh.'s und der folgezeit noch, nach $\mathrm{DWb}$. 9, 1081, 1 smirben) an, jedoch ohne die vermutung eines historischen zusammenhanges zwischen ihnen auszusprechen, zumal der beleg aus Oswald nur dem wörterbuche der Beda Weberschen ausgabe (vgl. no. LXVII, 4, 12 ebenda) entnommen ist.

Neidharts vergleich muss in Oberdeutschland zur sprichwörtlichen charakteristik der bauern geworden sein, wobei das tertium comparationis leicht verloren gieng. Eine derartige proverbielle verwendung der in ihrem wesen bereits unverstandenen phrase liegt bei Oswald vor, dem nur mehr die beziehung auf die bauern bekannt ist. Sie wird daher von ihm auch erweitert (und drisch den rossen fueter), bleibt aber als witz unwirksam, da nicht ersichtlich wird, inwieweit die angezogenen tätigkeiten den stand des verachteten bewerbers in gewolltem gegensatze $\mathrm{zu}$ dem des fräuleins abfällig-komisch charakterisieren sollen. Dass sich Oswald der entlehnung des gedankens, also des citates bewusst war, scheint der übrigens auch verallgemeinernde und so den eindruck des sprichwörtlichen bewirkende nachsatz als ander dein geslächt zu bekräftigen. Dafür ist auch anzuführen, dass Neidharts gedicht im 15. jh. in Oberdeutschland bekannt war; es ist nämlich in demselben alten drucke $z$ (Haupt s. vir ff.) enthalten, der hintereinander zwei Oswaldsche lieder (Schatz s. 48) in die sammlung der Neidharte einfügt, welche tatsache beweist, dass schon Oswalds zeitgenossen den engen zusammenhang seiner kunst und der Neidharts instinktiv richtig erkannt haben.

Aus diesen beziehungen scheint für die textgestalt der vorliegenden Oswaldstelle 80,39 f. der vorzug der von BC ge- 
brachten variante den für dein $\mathrm{A}$ zu resultieren, der zunächst dadurch an bedeutung gewinnt, dass $A$ und $B-C$ ist aus $B$ geflossen - durchaus gleichwertig sind. Obwol das possessivum an dieser stelle der anrede volkstümlicher ist als der blosse farblose artikel, bezeichnet gerade der den sprichwörtlichen charakter der phrase, auf den es ja dem dichter ankommt, wie der nachsatz als ander dein geslächt beweist, auffallend und deutlich. Ausserdem ist er metrisch noch günstiger als das possessivpronomen, das nur bei besonderer aufmerksamkeit des vortragenden ohne schwachen nebenton, d. i. ohne misverständlich wirkende betonung wegkommt.

GRAZ, december 1906.

ELVIRA SEVER.

\section{DIE ABFASSUNGSZEIT DES ACKERMANNS AUS BÖHMEN.}

Johannes von Saaz ist zur abfassung seines gesprächs zwischen ackermann und tod durch das ableben seiner gattin Margarete veranlasst worden. Nach seiner eigenen angabe $(19,13)$ starb sie am tage Petri kettenfeier (1. august) im jahre 6599 nach erschaffung; der welt. Danach bestimmt Knieschek in seiner ausgabe (s. 82), indem er die zählung des Eusebius zu grunde legt, der z. b. auch Berthold von Regensburg an zwei stellen $(1,72,13$. 381, 32) folgt (vgl. übrigens auch Pfeiffers anmerkung zur ersten stelle), 1399 als die gemeinte jahreszahl. Diese zahl ist dann in die literaturgeschichten übergegangen: vgl. z. b. Scherer s. 268; Vogt in Pauls Grundr.2 2, 1, 349.

Bei dieser zeitbestimmung hat sich nun Knieschek um ein jahr verrechnet. Nach der bestimmung des Eusebius, von der er mit recht ausgeht, verflossen von der schöpfung der welt bis zur geburt Christi im ganzen 5199 jahre. Diese von der von Johannes angegebenen zahl 6599 abgezogen, ergibt nicht 1399, sondern 1400 als das todesjahr Margaretens, also als früheste abfassungszeit des gesprächs. So hat schon der schreiber der erst nach Kniescheks ausgabe bekannt gewordenen Münchener handschrift die umrechnung vollzogen und die worte tausent vierhundes't eingeschoben (Anz.fda.4, 361). 'Diese jahreszahl ist also als terminus a quo festzuhalten. 